\title{
STRATEGI PRIORITAS PENENTUAN KEGIATAN USAHA PADA BADAN USAHA MILIK DESA
}

\author{
Boy Man \\ Sani Suhardiman \\ Program Studi Teknik Industri, Universitas Buana Perjuangan \\ JL.HS.ronggowaluyo telukjambe timur, karawang 41361 \\ email:boyman@ubpkarawang.ac.id \\ sani.suhardiman@ubpkarawang.ac.id
}

\begin{abstract}
Abstrak
\end{abstract}
Strategi dalam menentukan jenis kegiatan usaha baru yang di harapkan oleh Desa Tanjungpakis adalah jenis kegiatan Industri Kecil Menengah (IKM), industri kecil ini diharapkan dapat meningkatkan Pendapatan Asli Desa serta meningkatkan lapangan kerja dalam mengurangi angka pengangguran. Penggunaan metode dalam menentukan prioritas kegiatan pengembangan usaha baru, dengan menggunakan metode analisis menghasilakan kekuatan (Strength), kelemahan (Weaknesses), peluang (Opportunities), ancaman (Threats) SWOT dan Metode Matrik Perbanding Eksponesial (MPE).

Dari hasil analisis kondisi Desa berdasarkan potensi internal dan eksteranl yang dilakukan dengan metode SWOT, diperoleh skor total dari pengolahan data kuesioner Strength (4,08) dan Weaknesses (-2,78), sedangkan untuk total skor Opportunities $(3,78)$ dan Threats $(-2,84)$. Total skor hasil kuesioner kemudian dimasukan kedalam matrik SWOT kuadran, hasil skor sumbu y $(0,65)$ dan $x(0,06)$ menunjukan peluang ancaman yang ada dalam menentukan jenis kegiatan usaha dapat disesuaikan dengan kekuatan - kelemahan.

Berdasarkan hasil analisis SWOT dimana potensi desa yang mendukung berbagai jenis kegiata usaha dapat di ajukan sebagai rekomendasi, metode MPE digunakan untuk menentukan prioritas usaha. Hasil kriteria dan alternatif akan memunculkan nilai dari kuesiner MPE, dimana jenis usha pertambakan memiliki nilai tertinggi (12691), yang diikuti oleh pertambakan (8067), peternakan (841), jasa (66), dan perkebunan (55). Dari hasil penelitian diharapkan kegiatan usaha industri pakan dapat diterima dan terlaksana dalam memenuhi tujuan awal untuk perekonomian desa yang lebih baik.

Kata kunci : Strategi Priorita Penentuan, Analisa SWOT, Metode MPE

\section{Pendahuluan}

Keterlambatan pembangunan saat ini dikarenakan belum terbangunnya dengan baik pada perencanaan dalam penataan pembangunan, koordinasi dalam penataan/pembentukan regulasi pada masing-masing tingkatan baik Pusat, Provinsi maupun Kabupaten selalu tidak sejalan dan terus berbenturan, permasalahan internal dan eksternal lembaga pemerintahan.

Berdasarkan Rencana Induk Pembangunan Nasional (RIPIN) 2015-2035, pertumbuhan industri menargetkan mencapai 2 digit pada tahun 2035. 
Tabel 1.1 Sasaran Kuantitatif Pembangunan Industri

\begin{tabular}{|c|c|c|c|c|c|c|c|}
\hline No & Indikator Pembangunan Industri & Satuan & 2014 & 2015 & 2020 & 2025 & 2035 \\
\hline 1 & Pertumbuhan sektor Industri Non Migas & $\%$ & 5,7 & 6,8 & 8,5 & 9,1 & 10,5 \\
\hline 2 & Share Industri non migas terhadap PDB & $\%$ & 20,8 & 21,2 & 24,9 & 27,4 & 30,0 \\
\hline 3 & $\begin{array}{l}\text { Share ekspor produk industri terhadap } \\
\text { total ekspor }\end{array}$ & $\%$ & 66,5 & 67,3 & 69,8 & 73,5 & 78,4 \\
\hline \multirow[t]{2}{*}{4} & Jumlah tenaga kerja di sektor industri & $\begin{array}{l}\text { Juta } \\
\text { orang }\end{array}$ & 14,88 & 15,44 & 18,44 & 21,73 & 29,19 \\
\hline & $\begin{array}{l}\text { (Persentase tenaga kerja di sektor } \\
\text { industri terhadap total pekerja) }\end{array}$ & $\%$ & 13,7 & 14,1 & 15,7 & 17,6 & 22,0 \\
\hline 5 & $\begin{array}{l}\text { Rasio impor bahan baku sektor industri } \\
\text { terhadap PDB sektor industri non migas }\end{array}$ & $\%$ & 43,5 & 43,1 & 26,9 & 23,0 & 20,0 \\
\hline 6 & $\begin{array}{l}\text { Realisasi Nilai Investasi sektor industri } \\
\text { (Total PMA \& PMDN) }\end{array}$ & $\begin{array}{l}\text { Rp } \\
\text { Trilyun }\end{array}$ & 210 & 270 & 618 & 1.000 & 1.930 \\
\hline 7 & $\begin{array}{l}\text { Persentase nilai tambah sektor industri } \\
\text { yang diciptakan di luar Pulau Jawa }\end{array}$ & $\%$ & 29,00 & 30,00 & 32,00 & 35,00 & 40,00 \\
\hline
\end{tabular}

Sumber, RIPIN 2015-2035 (2014)

Dalam meningkatakan perekonomian Desa Tanjungpakis memiliki rencana dalam membangun kegiatan usaha baru, kegiatan usaha tersebut memiliki peluang kedepan untuk tetap bertahan dan berkembang. Masalah pokok dalam penelitian ini adalah melakukan Startegi Penentuan Kegiatan Usaha Baru Pada Badan Usaha Milik Desa di Desa Tangjungpakis, Kecamatan Pakisjaya, Kabupaten Karawang.

\section{Metodeologi Penelitian}

Populasi dalam penelitian ini adalah Kelompok Usaha, Potensi Desa, jenis kegiatan usaha dan permasalahan usaha yang ada di Desa Tanjungpakis yang berjumlah 7 unit kegiatan usaha. penentuan sample adalah dengan teknik Quota Sampling, pengambilan sample hanya berdasarkan pertimbangan penelitian saja, hanya disini besar kriteria dan sample telah ditentukan terlebih dahulu.

Penelitian ini menggunakan analisis kuantitatif dan kualitatif, analisis kuantitatif digunakan pada pengolahan data bervariasi dan banyak, sehingga dapat dikelompokan kedalam kategori berbentuk angka. Penggunaan metode untuk melakukan startegi dan menentukan jenis kegiatan usaha adalah metode Sternght, Weaknesses, Opportunities, Threats (SWOT) dan Matrik Perbanding Eksponensial (MPE). Sumber data yang digunakan utama dalam penelitian ini adalah data tambahan dokumen dan lain-lain. Variabel untuk penenlitian adalah modal, SDM, SDA, regulasi, kegiatan usaha.

\section{Hasil Penenlitian dan Pembahasan}

\section{Hasil Analisis SWOT}

Strategi Penentuan Prioritas Kegiatan Usaha Baru dilakukan dengan menganalisa kekuatan, kelemehan, maupun pelang serta ancaman. Analisis kondisi internal dan eksternal kemudian dilakukan penyebaran kuesioner, penggunaan kuesionr dilakukan untuk mengetahui kondisi Matrik IFAS dan EFAS dalam menentukan startegi dibawah ini.

\section{Responden}

Responden merupakan subjek penelitian dalam menguraikan atau memberikan gambaran mengenai kondisi lingkungan, sebab dengan menguraikan identitas 
responden. Dalam pelaksanaan penelitian ini ditetapkan 7 orang responden dari Pihak PEMDES yang diwakili oleh KADES sebagai penanggung jawab, Ketua BPD, dan Kelompok Usaha sebanyak 5 orang.

\section{Kuesioner}

Kuesiner merupakan daftar pertanyaan yang digunakan sebagai sarana dalam pengumpulan data untuk memperoleh gambaran yang sebenar-benarnya tentang sesuatu keadaan, kuesioner mempunyai peranan penting dalam mencapai tujuan dari analisis yang dilakukan. Untuk menghindari adanya kemungkinan tersebut, kuesioner yang digunakan adalah kuesioner penelitian skala likert sebagai instrument penelitian yang digunakan untuk mengumpulkan data primer dari responden. Kuesioner dibuat berdasarkan indikator-indikator penelitian yang diperoleh dari pengembangan hasil analisis.

Skala likert digunakan untuk mengukur Strengths, weaknesses, opportunities dan threats, jawaban dari setiap item instrumen pertanyaan yang menggunakan skala likert mempunyai gradasi dari terendah hingga sangat positif hingga negatif yang berupa:

Tabel 1.2. Skala Likert

\begin{tabular}{cl}
\hline $\mathbf{1}$ & Tidak baik \\
$\mathbf{2}$ & Kurang baik \\
$\mathbf{3}$ & Baik \\
$\mathbf{4}$ & Sangat baik \\
\hline
\end{tabular}

Pengumpulan data melalui kuesioner biasanya dilakukan melalui wawancara, baik secara lisan maupun tulisan, kuesioner sebenarnya sudah mencakup 2 jenis daftar isian pertama dan kedua dan sifatnya lebih luas dan lengkap. Hal ini disebabkan adanya dialog antara pewawancara dengan responden sehingga memungkinkan didapatkannya jawaban yang lebih akurat.

Tabel 1.3. Distribusi jawaban responden atas Kuesioner Faktor Internal dan Eksternal (SW)

\begin{tabular}{|c|c|c|c|c|c|c|c|c|c|c|c|c|c|}
\hline \multirow{2}{*}{\multicolumn{2}{|c|}{$\begin{array}{c}\text { Strategi } \\
\text { IFAS/EFAS }\end{array}$}} & \multirow{3}{*}{$\begin{array}{l}\text { Faktor-faktor } \\
\quad \text { Strategi }\end{array}$} & \multicolumn{7}{|c|}{ Responden } & \multirow{2}{*}{$\begin{array}{l}\text { Jml } \\
\text { Nilai }\end{array}$} & \multirow{2}{*}{ Bobot } & \multirow{2}{*}{$\begin{array}{c}\text { Ratin } \\
\mathrm{g}\end{array}$} & \multirow{2}{*}{ Skor } \\
\hline & & & 1 & 2 & 3 & 4 & 5 & 6 & 7 & & & & \\
\hline \multirow{4}{*}{ 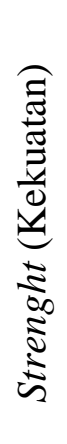 } & S1 & & 3 & 3 & 3 & 3 & 3 & 3 & 4 & 22 & 0,24 & 4 & 0,96 \\
\hline & $\mathrm{S} 2$ & $\begin{array}{l}\text { Sumber daya } \\
\text { manusia }\end{array}$ & 4 & 3 & 4 & 3 & 2 & 3 & 3 & 22 & 0,24 & 4 & 0,96 \\
\hline & S3 & $\begin{array}{l}\text { Banyaknya } \\
\text { kegiatan usaha }\end{array}$ & 4 & 3 & 3 & 4 & 3 & 4 & 4 & 25 & 0,27 & 4 & 1,08 \\
\hline & S4 & $\begin{array}{l}\text { Potensi sumber } \\
\text { daya alam }\end{array}$ & 4 & 4 & 4 & 3 & 3 & 3 & 4 & 25 & 0,27 & 4 & 1,08 \\
\hline \multicolumn{10}{|c|}{ Total } & 94 & 1,02 & & 4,08 \\
\hline$\frac{\sqrt{3}}{\frac{3}{2}}$ & W1 & $\begin{array}{c}\text { Minimnya } \\
\text { pengetahuan dan } \\
\text { kemampuan }\end{array}$ & 3 & 2 & 3 & 2 & 3 & 3 & 3 & 19 & 0,19 & -3 & $\begin{array}{c}- \\
0,57\end{array}$ \\
\hline
\end{tabular}




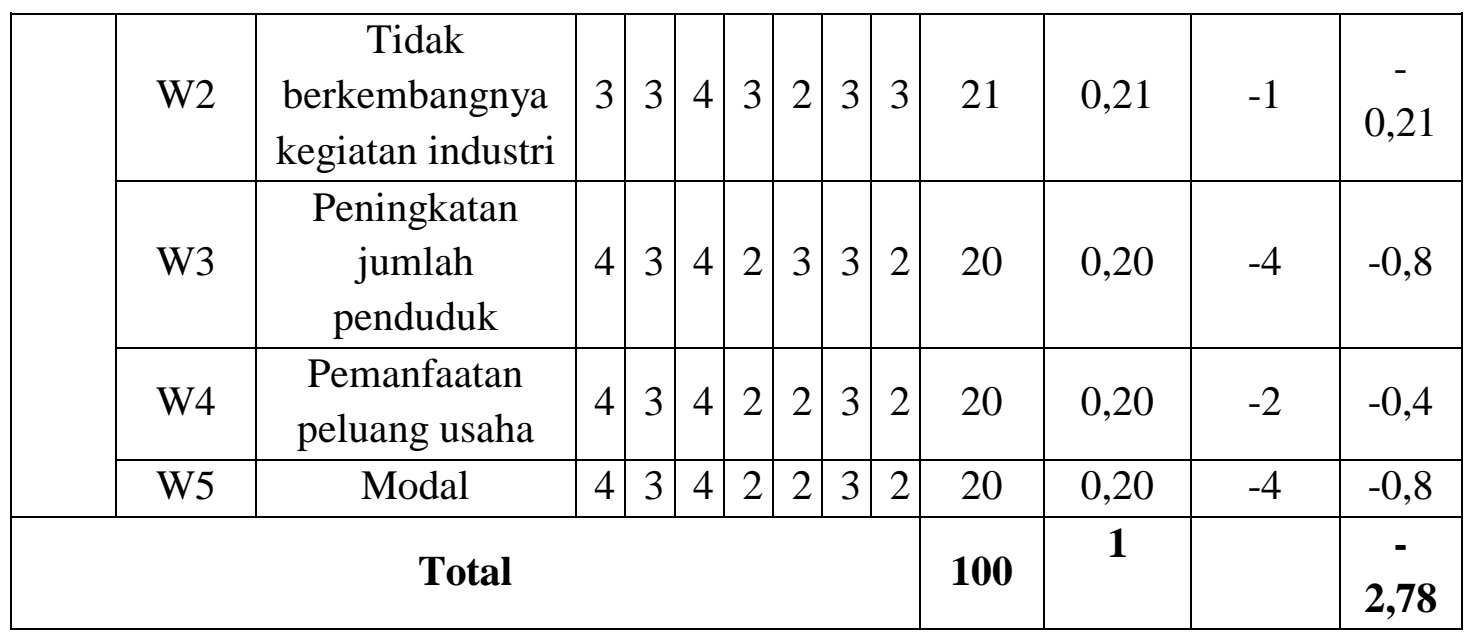

Tabel 1.4. Distribusi jawaban responden atas Kuesioner Faktor Internal dan Eksternal (OT)

\begin{tabular}{|c|c|c|c|c|c|c|c|c|c|c|c|c|c|}
\hline \multirow{2}{*}{\multicolumn{2}{|c|}{$\begin{array}{c}\text { Strategi } \\
\text { IFAS/EFAS }\end{array}$}} & \multirow{2}{*}{ Faktor-faktor Strategi } & \multicolumn{7}{|c|}{ Responden } & \multirow{2}{*}{$\begin{array}{l}\text { Jml } \\
\text { Nilai }\end{array}$} & \multirow{2}{*}{$\begin{array}{l}\text { Rata } \\
\text {-rata }\end{array}$} & \multirow{2}{*}{$\begin{array}{c}\text { Ratin } \\
\mathrm{g}\end{array}$} & \multirow{2}{*}{ Skor } \\
\hline & & & 1 & 4 & 3 & 4 & 5 & 6 & 7 & & & & \\
\hline \multirow{5}{*}{ 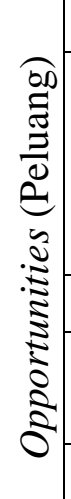 } & 01 & Banyaknya Investor & 3 & 3 & 4 & 4 & 3 & 4 & 4 & 25 & 0,24 & 3 & 0,72 \\
\hline & $\mathrm{O} 2$ & $\begin{array}{l}\text { Belum terliriknya } \\
\text { kegiatan usaha industri } \\
\text { kecil menengah berbasis } \\
\text { produksi }\end{array}$ & 3 & 2 & 2 & 4 & 3 & 3 & 3 & 20 & 0,18 & 4 & 0,72 \\
\hline & $\mathrm{O} 3$ & Banyaknya bantuan & 4 & 3 & 4 & 3 & 2 & 4 & 3 & 23 & 0,21 & 4 & 0,84 \\
\hline & $\mathrm{O} 4$ & $\begin{array}{l}\text { Tersedianya sumber daya } \\
\text { manusia dan alam }\end{array}$ & 3 & 3 & 4 & 2 & 3 & 3 & 4 & 22 & 0,20 & 4 & 0,8 \\
\hline & O5 & Kebijakan pemerintah & 3 & 3 & 4 & 3 & 2 & 3 & 4 & 22 & 0,20 & 3 & 0,6 \\
\hline \multicolumn{10}{|c|}{ Total } & 112 & 1,03 & & 3,68 \\
\hline \multirow{4}{*}{ 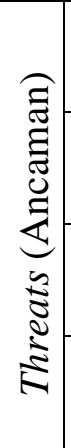 } & $\mathrm{T} 1$ & $\begin{array}{l}\text { Sumber daya manusia } \\
\text { yang tidak terkelola }\end{array}$ & 3 & 2 & 3 & 3 & 2 & 3 & 3 & 19 & 0,25 & -4 & -1 \\
\hline & $\mathrm{T} 2$ & $\begin{array}{l}\text { Perencanaan/program } \\
\text { pihak Desa }\end{array}$ & 3 & 3 & 3 & 3 & 2 & 3 & 3 & 20 & 0,26 & -2 & $0, \overline{52}$ \\
\hline & T3 & $\begin{array}{ll}\text { Tidak } & \text { responnya } \\
\text { masyarakat } & \end{array}$ & 3 & 2 & 4 & 3 & 3 & 3 & 3 & 21 & 0,27 & -4 & 1,08 \\
\hline & $\mathrm{T} 4$ & Alih fungsi lahan & 3 & 2 & 3 & 2 & 2 & 3 & 3 & 18 & 0,24 & -1 & $\overline{-}, 24$ \\
\hline \multicolumn{10}{|c|}{ Total } & 78 & 1,02 & & 2,84 \\
\hline
\end{tabular}

menunjukan bahwa hasil kuesioner menunjukan analisis IFAS dan EFAS menunjukan skor Kekuatan 4,08 terhadap Kelemahan -2,78, untuk Peluang sendiri memiliki skor 3,68 terhadap Ancaman -2,84. 


\section{Tabel matrik SWOT}

Tabel Matrik SWOT kekuatan dan kelemahan, peluang dan ancaman yang dihadapi oleh kelompok usaha ini dapat disesuaikan.

\subsection{Tabel Matrik SWOT}

\begin{tabular}{|c|c|c|}
\hline & Strenght (S) & Weaknesses (W) \\
\hline $\begin{array}{l}\text { Matriks } \\
\text { SWOT }\end{array}$ & $\begin{array}{l}\text { Program pemerintah } \\
\text { Sumber daya manusia } \\
\text { Banyaknya kegiatan } \\
\text { usaha } \\
\text { Potensi sumber daya } \\
\text { alam } \\
\text { (Bobot } 4,08)\end{array}$ & $\begin{array}{l}\text { Minimnya pengetahuan dan } \\
\text { kemampuan } \\
\text { Tidak berkembangnya kegiatan } \\
\text { industri } \\
\text { Peningkatan jumlah penduduk } \\
\text { Pemanfaatan peluang usaha } \\
\text { Modal } \\
\text { (Bobot }-2,78)\end{array}$ \\
\hline \multicolumn{3}{|l|}{ Opportunities (O) } \\
\hline $\begin{array}{l}\text { Banyaknya Investor } \\
\text { Belum terliriknya kegiatan } \\
\text { usaha industri kecil } \\
\text { menengah berbasis produksi } \\
\text { Banyaknya bantuan } \\
\text { Tersedianya sumber daya } \\
\text { manusia dan alam } \\
\text { Kebijakan pemerintah } \\
\text { (Bobot } 3,68)\end{array}$ & $\begin{array}{l}\text { Peluang Usaha (s3, } \\
\text { o3) } \\
\text { Penirngkatan } \\
\text { perekonomian } \\
\text { masyarakat (s4, o4, } \\
\text { o5) }\end{array}$ & $\begin{array}{l}\text { Penjalinan kemitraan terkait } \\
\text { permodalan, pemanfaatan } \\
\text { teknologi, serta pendampingan } \\
\text { pelaksanaan (w2, 02) } \\
\text { Penyediaan sarana dan } \\
\text { prasaranan (w3, o4, w4, o5) } \\
\text { Pemanfaatan teknologi tepat } \\
\text { guna (w2, w4, w5, o4) } \\
\text { (Bobot } 0,9)\end{array}$ \\
\hline Threat & & \\
\hline $\begin{array}{l}\text { Sumber daya manusia yang } \\
\text { tidak terkelola } \\
\text { Perencanaan/program pihak } \\
\text { Desa } \\
\text { Tidak responnya masyarakat } \\
\text { Alih fungsi lahan } \\
\text { (Bobot -2,84) }\end{array}$ & $\begin{array}{l}\text { Analisis potensi } \\
\text { kegiatan usaha (s3, s4, } \\
\text { t3, t4) } \\
\text { Pemanfaat SDA dan } \\
\text { SDM (s2, s3, s4, t1, } \\
\text { t3, t4) } \\
\text { (Bobot } 1,24)\end{array}$ & $\begin{array}{l}\text { Pelaksanaan program } \\
\text { pengembangan usaha }(\mathrm{w} 1, \mathrm{w} 2, \\
\mathrm{w} 4, \mathrm{w} 5, \mathrm{t} 1, \mathrm{t} 2, \mathrm{t} 3, \mathrm{t} 4 \\
\text { Kejelasan regulasi }(\mathrm{w} 5, \mathrm{t} 2)\end{array}$ \\
\hline
\end{tabular}

Strategi penentuan kegiatan usaha pada badan usaha milik desa berdasarkan hasil analisisi matrik SWOT untuk menyusun startegi dalam mengetahui antara kekuatan peluang, kekuatan - ancaman serta kelemahan - ancaman.

Hasil dari matrik interaksi IFAS-EFAS diatas, secara ringkas dapat dilihat pada tabel 5.4 .

Tabel 1.6. Pembobotan Hasil Kuesioner SWOT

\begin{tabular}{rcc}
\hline EFAS & $\mathrm{S}=4,08$ & $\mathrm{~W}=-2,76$ \\
$\mathrm{O}=3,68$ & $\mathrm{SO}=7,76$ & $\mathrm{WO}=0,92$ \\
$\mathrm{~T}=-2,84$ & $\mathrm{ST}=1,4$ & $\mathrm{WT}=-5,62$ \\
\hline
\end{tabular}


Berdasarkan pembobotan, maka disusun prioritas prioritas strategi berdasrkan kombinasi strategi yang memiliki nilai paling tinggi sampai paling rendah terdapat pada tabel 1.6.

Tabel 1.7. Urutan Alternatif Strategi SWOT

\begin{tabular}{ccc}
\hline Prioritas & Strategi & Bobot nilai \\
\hline I & Strengh - Opportunity $(S O)$ & 1,24 \\
II & Strengh - Thereat $($ ST) & 1,3 \\
III & Weakness - Opportunity $(W O)$ & 0,9 \\
IV & Weakness - Threat $(W T)$ & $-5,62$ \\
\hline
\end{tabular}

Urutan strategi akternatif dari IFAS-EFAS pada tabel diatas menunjukan bahwa alternatif strategi dengan bobot tertinggi adalah startegi Strengh - Thereat (ST), dari perolehan bobot tertinggi dapat disimpulkan ST sebagai startegi yang menimalkam kekuatan yang ada untuk memanfaatkan peluang.

a. Selain pariwisata beberapa jenis kegiatan usaha tambak bandeng dan budidaya udang hasil laut juga merupakan potensi, karena pada umumnya masyarakat beramata pencaharian sebagai nelayan.

b. Peningkatan Perekonomian di Kabupaten Karawang khususnya di pedesaan bisa dilakukan, potensi sumber daya manusia dan alam yang berlimpah, dan hingga saat ini belum ada kebijakan pemerintah yang benar-benar terfokus pada pembangunan industri menengah kecil secara serius dan berkesinambungan.

c. Penjalinan kemitraan baik dengan PEMDES bukan tidak bisa membangun usaha karena keterbatasan pembagian anggaran, sedangkan hanya dengan mengandalkan program bantuan dari pemerintah itu pun tidak mencukupi, jika kondisi seperti ini dibiarkan maka desa akan tertinggal disegala sektor.

d. Pemberdayaan masyarakat melalui penyediaan sarana dan prasarana sesuai dengan potensi merupakan salah satu startegi dalam membuka peluang usaha, dengan modal yang tidak terlalu banyak dan hasil yang diperoleh dapat mencukupi kebutuhan masyarakat untuk mencapai taraf hidup berkecukupan merupakan peluang didalam mensejahterahkan masyarakat.

e. Peningkatan jumlah penduduk yang tidak diiringi oleh kemampuan manusia, dalam memanfaatkan atau menggunakan teknologi akan tertinggal oleh sumber daya manusia yang berkompeten.

f. Analisis potensi kegiatan usaha dari beberapa kegiatan usaha yang telah dilakukan di lingkungan sekitar, adalah salah satu cara pemanfaatan potensi kekayaan desa yang sudah seharusnya dilakukan secara bersama-sama.

g. Pemanfaatan SDA dan SDM melalui program-program yang disalurkan pemerintah, dalam memanfaatkan ketersediaan harus terlebih dahulu disesuaikan. Perencanaan melalui program pelatihan bagi masyarakat kunci agar membantu memaksimalkan program pemerintah didalam memeratakan kegiatan usaha khususnya skala kecil.

h. Pelaksanaan program pengembangan usaha didalam menarik minat masyarakat melalui bantuan permodalan untuk membuka kegiatan usaha, adalah cara meminimalisir tidak berjalannya kegiatan usaha yang hanya berorientasi kepada keuntungan tanpa mempertimbangakan pengembangan usaha sesuai dengan perencanaan. 
i. Kebijakan regulasi merupakan salah satu kunci yang dimiliki oleh pemerintah kabupaten melalui otnomi daerah, dimana otda tersebut memperbolehkan wilayah tersebut merencanakan dan membangun sesuai kebutuhan kabupaten/kota.

\section{Hasil Analisis Matrik Perbandingan Eksponensial}

Beberapa alternatif jenis kegiatan usaha yang dimasukan perhitungan MPE pada tabel 5.6 menunjukan bahwa alternatif kegiatan usaha Pertambakan, Peternakan, Jasa, Perkebunan dan Industri Pakan menunjukan Industri Pakan merupakan alternatif usaha dengan nilai 12691.

Tabel 1.8. Perhitungan MPE

\begin{tabular}{|c|c|c|c|c|c|c|c|c|c|c|}
\hline \multirow[b]{2}{*}{ Alternatif } & \multicolumn{9}{|c|}{ Kriteria (Range 1-5) } & \multirow[b]{2}{*}{$\begin{array}{l}\text { Nilai } \\
\text { MPE }\end{array}$} \\
\hline & $\begin{array}{c}\text { Bobot } \\
(1-5)\end{array}$ & $\begin{array}{c}\text { Peluang } \\
\text { Usaha }\end{array}$ & $\begin{array}{c}\text { Peningkatan } \\
\text { Perekonomian } \\
\text { Masyarakat }\end{array}$ & Kemitraan & Regulasi & $\begin{array}{c}\text { Penyediaan } \\
\text { Fasilitas }\end{array}$ & $\begin{array}{l}\text { Pemanfaat } \\
\text { Teknologi }\end{array}$ & $\begin{array}{c}\text { Pemanfaatan } \\
\text { SDA \& } \\
\text { SDM }\end{array}$ & Program & \\
\hline Pertambakan & 5 & 5 & 4 & 5 & 3 & 3 & 2 & 2 & 3 & 8067 \\
\hline Peternakan & 5 & 3 & 2 & 3 & 3 & 2 & 2 & 1 & 3 & 841 \\
\hline Jasa & 2 & 2 & 4 & 3 & 2 & 4 & 3 & 2 & 2 & 66 \\
\hline Perkebunan & 3 & 2 & 2 & 1 & 3 & 1 & 1 & 2 & 1 & 55 \\
\hline $\begin{array}{l}\text { Industri } \\
\text { Pakan }\end{array}$ & 5 & 5 & 4 & 4 & 1 & 4 & 5 & 3 & 5 & 12691 \\
\hline
\end{tabular}

Setalah melakukan bobot nilai, maka pada lima kolom alternatif kegiatan usaha, Kemudian dilakukan perhitungan dari hasil pengisian nilai terhadap kriteria dengan melakukan pemangkatan nilai terhadap bobot dan kemudian di jumlahkan, berikut tiga kegiatan usaha dengan nilai MPE tertinggi:

Tabel 5.9. Prioritas Alternatif MPE Tertinggi

\begin{tabular}{clc}
\hline Prioritas & \multicolumn{1}{c}{ Alternatif terpilih } & Nilai MPE \\
\hline Jenis kegiatan usaha 1 & Industri Pakan & 12691 \\
Jenis kegiatan usaha 2 & Pertambakan & 8067 \\
Jenis kegiatan usaha 3 & Peternakan & 841 \\
Jenis kegiatan usaha 4 & Jasa & 66 \\
Jenis kegiatan usaha 5 & Perkebunan & 55 \\
\hline \multicolumn{2}{c}{ Jumlah } & 21720 \\
\hline
\end{tabular}

Dari hasil penjumlahan maka nilai MPE terbesar dari berbagai alternatif kegiatan usaha diatas industri pakan sebesar 58,4\% dan inndustri pakan yang merupakan alternatif usulan kegiatan usaha baru dapat direkomendasikan kepada PEMDES Tanjungpakis, BUMDes dan kelompok binaan untuk mengembangkan kegiatan usaha milik pemerintah Desa Tanjungpakis. Hasil pesentasi pada industri pakan adalah dengan jumlah total nilai MPE dari kelima alternatif jenis usaha tersebut adalah:

a. Alternatif jenis kegiatan usaha kesatu Industri Pakan

$$
\frac{12691}{21720} \times 100 \%=58,4 \%
$$

b. Alternatif jenis kegiatan usaha kedua adalah Pertambakan

$$
\frac{8067}{21720} \times 100 \%=37,1 \%
$$

c. Alternatif jenis kegiatan usaha ketiga adalah Peternakan 


$$
\frac{841}{21720} \times 100 \%=1,44 \%
$$

d. Alternatif jenis kegiatan usaha keempat adalah Jasa

$$
\frac{66}{21720} \times 100 \%=0,31 \%
$$

e. Alternatif jenis kegiatan usaha keempat adalah Perkenunan

$\frac{55}{21720} \times 100 \%=0,26 \%$

\section{Pembahasan Hasil Metode SWOT dam MPE}

Dalam melakukan penentuan prioritas jenis kegiatan usaha baru dalam mengembangkan usaha BUMDes, analisis terhadap faktor internal dan eksternal berdasarkan kekuatan, kelemahan, peluang dan ancaman merupakan sumber yang digunakan untuk dapat memunculkan faktor-faktor strategi beserta indikator pendukung agar penentuan startegi dalam menyimpulkan langkah-langkah yang akan dilakukan.

\section{Gambar 5.1 Kudaran SWOT}

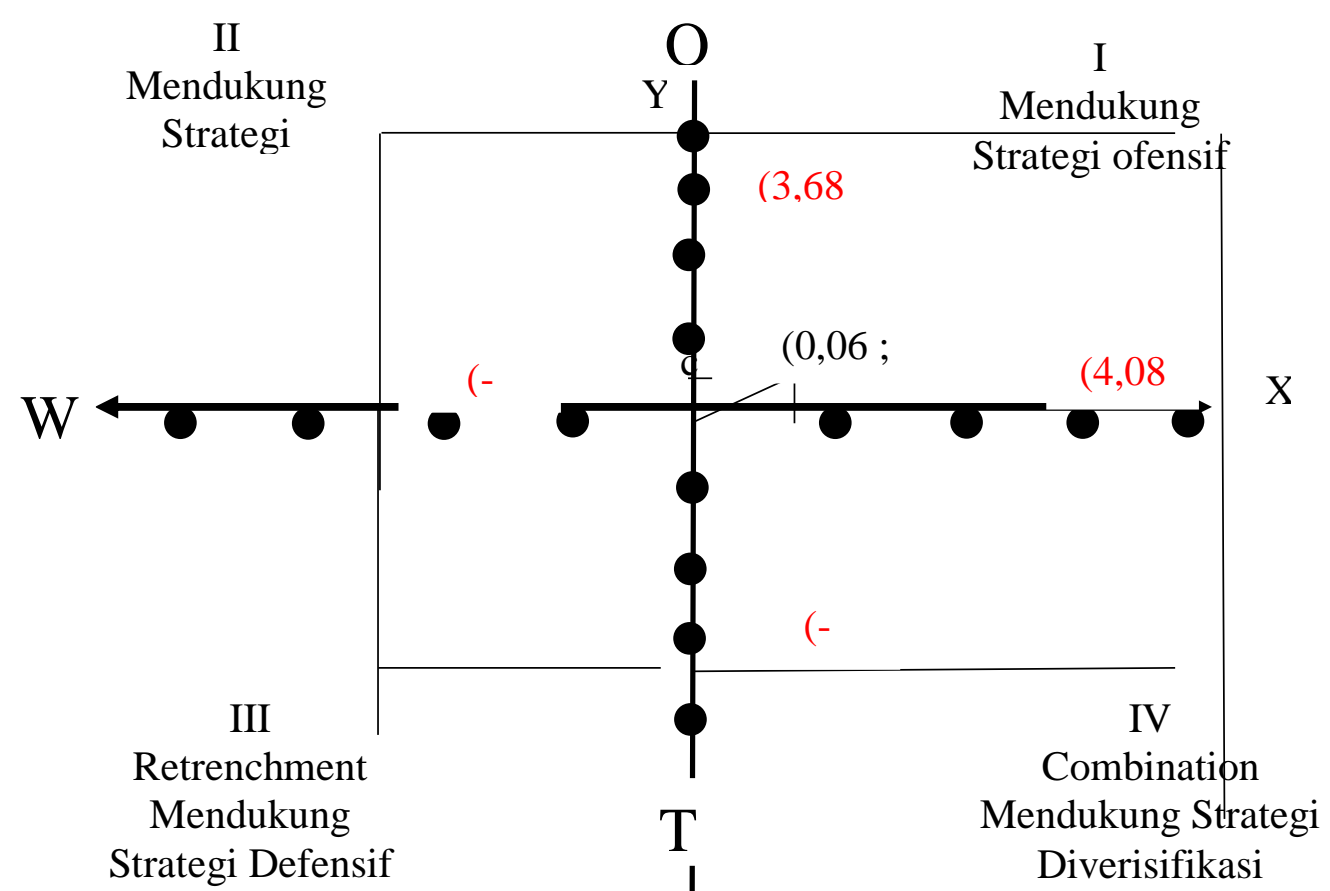

Hasil dari pengelolaan kuesioner SO metnperoleh bobot prioritas paling tinggi, regulasi, permodalan, investor dan hal yang paling utama adalah merencanakan kegiatan usaha baru. analisis MPE bahwa industri pakan merupakan kegiatan usaha memiliki skor tertinggi. Rekomendasikan kegiatan usaha baru dengan mengakumulasi MPE dalam merekomendasikan usulan yang telah dilakukan melalui berbagai proses.

a. Alternatif jenis kegiatan usaha kesatu Industri Pakan

$$
\frac{12691}{21720} \times 100 \%=58,4 \%
$$

b. Alternatif jenis kegiatan usaha kedua adalah Pertambakan 


\section{$\frac{8067}{21720} \times 100 \%=37,1 \%$}

c. Alternatif jenis kegiatan usaha ketiga adalah Peternakan

$$
\frac{841}{21720} \times 100 \%=1,44 \%
$$

d. Alternatif jenis kegiatan usaha keempat adalah Jasa

$$
\frac{66}{21720} \times 100 \%=0,31 \%
$$

e. Alternatif jenis kegiatan usaha keempat adalah Perkenunan

$$
\frac{55}{21720} \times 100 \%=0,26 \%
$$

Alternatif kegiatan usaha pilihan dengan metode MPE industri pakan merupakan usulan kegiatan usaha berdasarkan permasalah pada kegiatan usaha tambak dan peternakan dilingkungan Desa tanjungpakis.

\section{Daftar Pustaka}

Kementrian Perindustrian. (2014). Pembahasan Rancangan Peraturan Pemerintah Tentang Rencana Induk Pembangunan Industri Nasional (RIPIN) 2015-2035.

Buyukozkan G, Feyzioglu O, Nebol O. (2008). Selection of the strategic alliance partner in logistics value chain. Int production econmics. 113 148-158.

Yang H. D, Kim S, Nam C, Min W. J. (2007). Developing a decision model for business process outsourcing. Computers \& operation research. 34 3769-3778.

Chen M. K, Wang S. C. (2010). The critical factors of succes for information service industry in developing internatinal market: using analytic hierarchy process (AHP) approach. Expert system with applications. 37 694-704.

Hanfield R, Walton V. S, Sroufe R, Melnky S, A. (2002). Applying environmental criteria to supplier assessment: A study in the application of the analytical kierarchy process. European journal of operational research. 141 70-87.

Dagdeviren M, Yuksel I. (2008). Developing a fuzzy analytic hierarchy process (AHP) model for behavior-based safety management. Information sciences

Kajanus M, Kangas J, Kurttila M. (2004). The use of value focused thinking and the A'WOT hybird method in tourism management. Tourism management. 25 499-506. 
Bernroider E. (2002). Factor in SWOT analysis applied to micro, small-to-medium, and large software enterprises: an austrian syudy. European journal of operational research vol. 20 (6) 0263-2373.

Dyson R. G. (2004). Strategic development and SWOT analysis at the Univesity of warwick. European journal of operational research. 152 631-640.

Yuksel I, Dagdeviren M. (2007). Using the analytic network process (ANP) in a SWOT analysis-A case study for a textile firm. Information sciences. 117 3364-3382.

Agustinus Sri Wahyudi. (2002). Manajemen Strategik: Binarupa Aksara

Hill T, Westbrook R. (1997). SWOT Anlysis: it's Time for a Product Recall. Long Range Planning. vol. 30 (96) 0024-6301

Tunc Bozbura F, Beskese A, Kahraman C. (2007). Prioritization f human capital measurement indicator using fuzzy AHP. Expert system with applications 32 1100-1112

Kurttila M, Pesonen M, Kangas J, Kajanus M. (2000). Utilizing the analytic hierarchy process 